\title{
Postsynaptic Calcium Transients Evoked by Activation of Individual Hippocampal Mossy Fiber Synapses
}

\author{
Christopher A. Reid, ${ }^{1}$ Ruth Fabian-Fine, ${ }^{2}$ and Alan Fine ${ }^{1,3}$ \\ 1Division of Neurophysiology, National Institute for Medical Research, London NW7 1AA, United Kingdom, ${ }^{2}$ Department \\ of Biological Sciences, The Open University, Milton Keynes MK7 6AA, United Kingdom, and ${ }^{3}$ Department of Physiology \\ and Biophysics, Faculty of Medicine, Dalhousie University, Halifax, Nova Scotia B3H 4H7, Canada
}

Control of $\mathrm{Ca}^{2+}$ within dendritic spines is critical for excitatory synaptic function and plasticity, but little is known about $\mathrm{Ca}^{2+}$ dynamics at thorny excrescences, the complex spines on hippocampal CA3 pyramidal cells contacted by mossy fiber terminals of dentate granule cell axons. We have monitored subthreshold stimulus-dependent postsynaptic $\mathrm{Ca}^{2+}$ transients in optically and ultrastructurally characterized complex spines and find that such spines can act as discrete units of $\mathrm{Ca}^{2+}$ response. In contrast to the more common "simple" spines, synaptically evoked $\mathrm{Ca}^{2+}$ transients at complex spines have only a small NMDA receptor-dependent component and do not involve release of calcium from internal stores. Instead, they result mainly from AMPA receptor-gated $\mathrm{Ca}^{2+}$ influx through voltage-activated calcium channels on the spine; these channels provide graded amplification of the response of thorny excrescences to individual mossy fiber synaptic events.

Key words: hippocampus; dendritic spine; mossy fiber synapse; CA3 pyramidal neuron; calcium dynamics; subthreshold stimulation; active spine membrane; voltage-activated calcium channels; thorny excrescence; electron microscopy
Most excitatory synapses within the CNS are made on dendritic spines. The precise role of these structures is unknown, although they are thought to act as compartments for postsynaptic integration of biochemical signals (Segal, 1995; Denk et al., 1996; Shepherd, 1996; Svoboda et al., 1996). $\mathrm{Ca}^{2+}$ acts as a key second messenger in many biochemical cascades, and the control of $\mathrm{Ca}^{2+}$ dynamics within spines is critical for certain forms of synaptic plasticity (Bliss and Collingridge, 1993). Through the use of intracellular fluorescent $\mathrm{Ca}^{2+}$ indicators, it is now possible to monitor the synaptic activation of individual dendritic spines (Müller and Connor, 1991; Malinow et al., 1994; Yuste and Denk, 1995; Emptage et al., 1999; Mainen et al., 1999), permitting the study of these processes with hitherto unattainable spatial resolution.

Hippocampal CA3 pyramidal neurons have two quite different classes of spines. Commissural-associational and recurrent collateral inputs contact the more common form of structurally simple dendritic spines, found in abundance throughout most of the dendritic arbor. In contrast, dentate granule cell axons (mossy fibers) synapse on large and complex dendritic spines, known as thorny excrescences (Ramon y Cajal, 1911), located mainly on the proximal apical dendrite and soma (Chicurel and Harris, 1992). Multiple protrusions of these spines are interdigitated with protrusions of the large mossy fiber terminals, with discrete postsynaptic densities apposed to multiple presynaptic release sites.

Received Oct. 20, 2000; revised Dec. 15, 2000; accepted Dec. 22, 2000.

This work was supported by the Medical Research Council of the United Kingdom and the Human Frontier Science Program. C.A.R. is a Howard Florey Fellow of the Royal Society. We thank T. Bliss, N. Emptage, D. Rusakov, and M. Takahashi for helpful comments, and S. Dhanjal, G.-L. Raimondi, G. Roalfe, and the Mechanical Engineering Section of the National Institute for Medical Research for technical assistance.

Correspondence should be addressed to Alan Fine, Division of Neurophysiology, National Institute for Medical Research, The Ridgeway, Mill Hill, London NW7 1AA, UK. E-mail: afine@nimr.mrc.ac.uk.

Copyright $\odot 2001$ Society for Neuroscience $0270-6474 / 01 / 212206-09 \$ 15.00 / 0$
Several studies have described subthreshold stimulus-dependent postsynaptic $\mathrm{Ca}^{2+}$ transients at simple spines on hippocampal (Malinow et al., 1994; Yuste and Denk, 1995; Emptage et al., 1999; Mainen et al., 1999; Yuste et al., 1999; Kovalchuk et al., 2000) and neocortical (Koester and Sakmann, 1998) pyramidal neurons. These $\mathrm{Ca}^{2+}$ transients appear primarily dependent on NMDA receptor-mediated glutamatergic transmission (Emptage et al., 1999; Yuste et al., 1999), although the relative contributions of other sources of $\mathrm{Ca}^{2+}$, including voltage-activated calcium channels (VACCs) (Magee et al., 1995; Schiller et al., 1998) and calcium-induced calcium release (CICR) from internal stores (Emptage et al., 1999; Kovalchuk et al., 2000), is controversial.

Less is known about the control of postsynaptic $\mathrm{Ca}^{2+}$ dynamics at the complex mossy fiber synapse. Here, we show that complex spines at mossy fiber synapses can act as discrete units of $\mathrm{Ca}^{2+}$ response. Using pharmacological manipulations to establish the relative contributions of potential $\mathrm{Ca}^{2+}$ sources, we demonstrate that, in contrast to simple spines, synaptically evoked $\mathrm{Ca}^{2+}$ transients at complex spines are only partially dependent on NMDA receptor activation and appear to result mainly from $\mathrm{Ca}^{2+}$ influx through VACCs activated by AMPA receptor-mediated depolarization.

\section{MATERIALS AND METHODS}

Preparation of organotypic hippocampal cultures. Transverse $350-\mu \mathrm{m}$-thick slices of hippocampus were cut from 8-d-old male Wistar rat pups and cultured on Millicell CM (Millipore, Bedford, MA) membranes at a gas-liquid interface (Stoppini et al., 1991) for 10-21 d before use.

Electrophysiological and optical recording. Cultures on their supporting membrane were transferred to a recording chamber in which they were continually superfused with oxygenated $\left(95 \% \mathrm{O}_{2}-5 \% \quad \mathrm{CO}_{2}\right)$ artificial CSF (ACSF) maintained at $30^{\circ}-32^{\circ} \mathrm{C}$ (temperature controller; Scientific System Design, Montclair, NJ). A translation stage permitted the chamber and micromanipulators to be moved smoothly as a unit. Except where 
noted, the ACSF contained (in mM): $120 \mathrm{NaCl}, 3 \mathrm{KCl}, 2 \mathrm{MgSO}_{4}, 3$ $\mathrm{CaCl}_{2}, 1.2 \mathrm{NaHPO}_{4}, 23 \mathrm{NaHCO}_{3}, 11$ glucose, and 1 of the anti-oxidant Trolox. Slices were viewed through a Leica (Wetzlar, Germany) DMLSF upright microscope using an Olympus Optical (Tokyo, Japan) waterimmersion $60 \times$ numerical aperture 0.9 objective and a Bio-Rad (Hercules, CA) MRC600 confocal laser scan head. Pyramidal cells in the CA3 region of organotypic hippocampal cultures were impaled with sharp microelectrodes (100-180 M $\Omega$, with filament) tip filled with $0.5-1 \mathrm{~mm}$ Oregon Green 488 BAPTA-1 (Molecular Probes, Eugene, OR) in 200 mM potassium acetate and backfilled with 4 M potassium acetate; $N$-(2,6dimethylphenylcarbamoylmethyl)triethylammonium bromide (QX-314) $(50 \mathrm{~mm})$ was included in some experiments. To facilitate subsequent preparation for electron microscopy (see below), microelectrodes in some cases also contained 2\% Cascade Blue biocytin (Molecular Probes). The indicator was injected into the cell by applying hyperpolarizing current (0.05-0.1 nA) for 5-20 min via an Axoclamp 2B amplifier (Axon Instruments, Foster City, CA). Stimuli (single 40-100 $\mu$ sec square pulses, or pairs separated by $70-75 \mathrm{msec}$ ) were delivered via a sharpened monopolar tungsten stimulating electrode (A-M Systems, Carlsborg, WA) placed in the cell body layer of the dentate gyrus. The proximal region of the apical dendrite of the CA3 pyramidal neuron was searched while stimulating at $\sim 0.05 \mathrm{~Hz}$, until a spine exhibiting stimulusevoked calcium transients was found. Two-dimensional confocal scans lack the temporal resolution required for accurate measurement of these calcium transients, so the confocal microscope was used in line scan mode. Line scans consisted of 256 successive sweeps, at $2 \mathrm{msec}$ intervals, across a single line in the field of view. The orientation of the line was optimized using a scan rotator (Scientific System Design), and a custommade time stamp was used to mark a white line in the line scan, which coincided with the precise time of stimulation. Electrophysiological data were captured using A/DVANCE software (McKeller Designs, Vancouver, Canada), and images were collected using COMOS software (Bio$\mathrm{Rad})$. Images and electrophysiological data were analyzed using NIH Image and Axograph (Axon Instruments) software, respectively. The calcium transient amplitudes were expressed as percent fractional change in fluorescence, calculated as $100\left(F-F_{\text {initial }}\right) /\left(F_{\text {initial }}-F_{\text {background }}\right)$. To improve the signal-to-noise ratio, we measured $\Delta F / F$ over a $30 \mathrm{msec}$ window at the peak of the $\mathrm{Ca}^{2+}$ transient. Changes in $\Delta F / F$ after drug manipulations were expressed as normalized percent relative to $\Delta F / F$ before drug application (baseline); controls were exposed to ACSF changes at the corresponding times. Statistical comparisons were made with Student's $t$ test, two-tailed except where indicated. 6-Cyano-7-nitroquinoxaline-2,3-dione (CNQX), D-(-)-2-amino-5-phosphonovaleric acid (D-APV), (2S, $\left.2^{\prime} R, 3^{\prime} R\right)-2-\left(2^{\prime}, 3^{\prime}\right.$-dicarboxycyclopropyl)glycine (DCG-IV), $\mathrm{N}$-(4-hydroxyphenylpropanoyl)spermine trihydrochloride (HPP-spermine), (+)-5-methyl-10,11-dihydro-5H-dibenzo [a,d] cyclohepten-5,10-imine maleate (MK-801), and QX-314 were obtained from Tocris Cookson (Ballwin, MO), Trolox was obtained from Aldrich (Milwaukee, WI), and all other reagents were obtained from Sigma (St. Louis, MO).

Electron microscopic visualization of characterized synapses. Cascade Blue-coinjected preparations were, after imaging and electrophysiological recording, fixed in 3\% paraformaldehyde $-0.3 \%$ glutaraldehyde in 0.1 $\mathrm{M}$ PBS, $\mathrm{pH} 7.4$, for $20 \mathrm{~min}$ at $4^{\circ} \mathrm{C}$. Before osmication and embedding, the preparation was trimmed under fluorescence microscopic observation to include only the filled neuron and its immediate environs. The reduced preparation was rinsed in PBS (four times for $5 \mathrm{~min}$ each) and osmicated $\left(0.5 \% \mathrm{OsO}_{4}\right.$ in $\left.\mathrm{PBS}\right)$ for $4-7 \mathrm{~min}$. After subsequent rinsing in PBS (three times for $5 \mathrm{~min}$ each), preparations were dehydrated in a graded series of ethanol and embedded in Araldite (Agar Scientific, Stansted, UK). The resin was polymerized overnight in embedding molds at $60^{\circ} \mathrm{C}$. Serial ultrathin sections $(75 \mathrm{~nm})$ were cut with a Reichert Ultracut and collected on pioloform-coated single slot grids. Sections were contrasted with uranyl acetate and Reynold's lead citrate according to standard EM methods and were examined using a Jeol (Peabody, MA) JEM-1010 electron microscope.

\section{RESULTS}

\section{Identification of complex dendritic spines postsynaptic to mossy fiber terminals}

Individual pyramidal cells in the CA3 region of organotypic hippocampal slice cultures were filled with the high-affinity fluo- rescent $\mathrm{Ca}^{2+}$ indicator Oregon Green 488 BAPTA-1 and imaged by laser-scanning confocal microscopy (Fig. $1 A$ ). Visual criteria were used to identify dendritic spines postsynaptic to mossy fiber terminals; spines were located on the proximal apical dendrite within $100 \mu \mathrm{m}$ of the soma and were large, with heads $2-5 \mu \mathrm{m}$ in diameter (Chicurel and Harris, 1992). Furthermore, many of the spines investigated here could be seen by confocal microscopy to have a complex, lobular appearance (Fig. 2B). To maximize the likelihood of stimulating mossy fibers, the extracellular stimulating electrode was placed in the dentate granule cell body layer (Fig. $1 B$ ) to elicit EPSPs in the impaled cell. The mossy fiber origin of the EPSP was supported by its short latency and, pharmacologically, by inhibition of the synaptic response using DCG-IV $(1 \mu \mathrm{M})$, a selective group II metabotropic glutamate receptor (mGluR) agonist (EPSP amplitudes reduced to $8 \pm 1 \%$ of control; $p<0.05 ; n=3$ ) (Fig. 1C); group II mGluRs are expressed exclusively on mossy fiber terminals in CA3 (Kamiya et al., 1996; Shigemoto et al., 1997).

\section{Single synaptic events elicit calcium transients within individual complex spines}

Stimulation in the dentate granule cell layer resulting in subthreshold EPSPs in the indicator-filled CA3 pyramidal neurons was typically found to be associated with a rapid increase in $\mathrm{Ca}^{2+}$ indicator fluorescence in one or a few complex dendritic spines, as illustrated in Figure 2. The line scan trajectories, marked by the pairs of arrows, pass through a number of spines, of which only one in each case exhibited a rapid increase in fluorescence after some (Fig. $2 A i, B i, C i$ ) but not all (Fig. $2 A i i, C i i)$ afferent stimuli. In contrast, when the stimulus strength was increased to elicit an action potential, all imaged spines (as well as the dendrite and soma) exhibited a simultaneous increase in fluorescence (Fig. 2Bii). The synaptically evoked postsynaptic $\mathrm{Ca}^{2+}$ transients (EPSCaTs) at these complex spines are large (fractional change in intensity, $\Delta F / F=84 \pm 7 \% ; n=31)$, with a rapid rise $(<8 \mathrm{msec})$ and slower decay $(\tau=168 \pm 16 ; n=12)$. EPSCaT amplitudes were not limited by saturation of the high-affinity $\mathrm{Ca}^{2+}$ indicator because, when stronger stimuli elicited action potentials (presumably by recruitment of additional fibers synapsing elsewhere on the cell) (Fig. 2Bii), this in all cases resulted in larger $\mathrm{Ca}^{2+}$ transients at the interrogated spine $(\% \Delta F / F=111 \pm 14 \%$ for suprathreshold EPSPs vs $67 \pm 9 \%$ for subthreshold EPSPs; $p<$ $0.0005 ; n=13$ ).

In over $90 \%$ of spines studied, the EPSCaT was restricted to the spine (Fig. 2Ai, Ci,Cii); in 11 cases in which the scan path was perpendicular to the long axis of the dendrite, the mean fluorescence transient $(\Delta F / F)$ in the dendritic shaft directly beneath the spine was $3.2 \pm 1.6 \%$ compared with $92 \pm 14 \%$ in the spine head. These observations indicate that, as with more simple spines, the complex "thorny excrescence" spine is a discrete compartment of postsynaptic $\mathrm{Ca}^{2+}$ response.

Calcium transients at thorny excrescences were not invariably evoked by every stimulus (Fig. 2Aii,Cii). We have demonstrated previously (Emptage et al., 1999) that the probability of obtaining an EPSCaT $\left(p_{\mathrm{Ca}}\right)$ can be used to estimate the transmitter release probability $\left(p_{\mathrm{r}}\right)$ at simple synapses. Mossy fiber boutons display multiple discrete active zones (potential transmitter release sites) opposite postsynaptic densities on CA3 complex spines (Chicurel and Harris, 1992), so that the effective $p_{\mathrm{r}}$ at these synapses is an aggregate probability reflecting both $p_{\mathrm{r}}$ at each release site and the total number of these sites. Paired-pulse facilitation, the phenomenon in which the EPSP to a second closely-following 


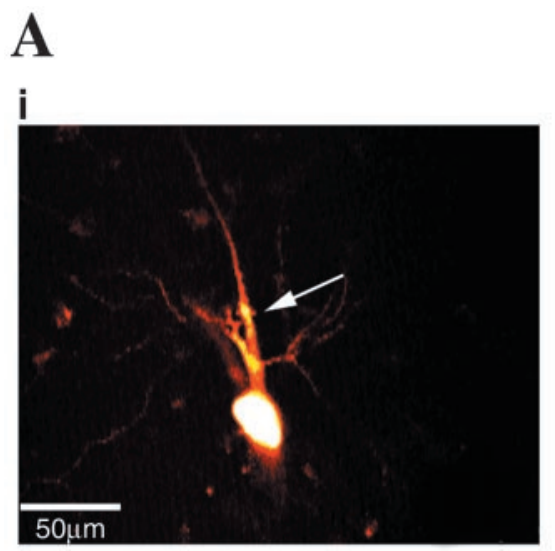

Figure 1. Identification of complex dendritic spines at mossy fiber synapses. $A_{i}$, A living CA3 pyramidal neuron in an organotypic hippocampal slice, after filling with the calcium indicator Oregon Green 488 BAPTA-1. The arrow indicates a complex spine on the primary apical dendrite of the CA3 pyramidal neuron. $A_{i i}$, Enlarged view showing the location, large size, and shape of the complex spine. $B$, Illustration of electrode placement in the organotypic hippocampal cultures. The stimulating electrode was positioned in the dentate granule cell body layer to maximize the likelihood of selectively stimulating the mossy fibers projecting from these cells to the proximal dendrites of CA3 pyramidal neurons. $C$, DCG-IV $(1 \mu \mathrm{M})$, a selective group II metabotropic glutamate receptor agonist, significantly reduces the EPSP-IPSP, confirming its mossy fiber origin $\left({ }^{*} p<0.05\right.$, significantly different from control). Inset traces show EPSP-IPSPs in the absence and presence of DCG-IV; resting potential, $-76 \mathrm{mV}$.

ii

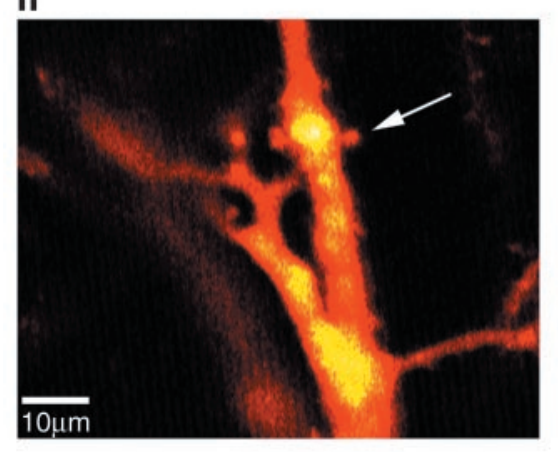

\section{B}

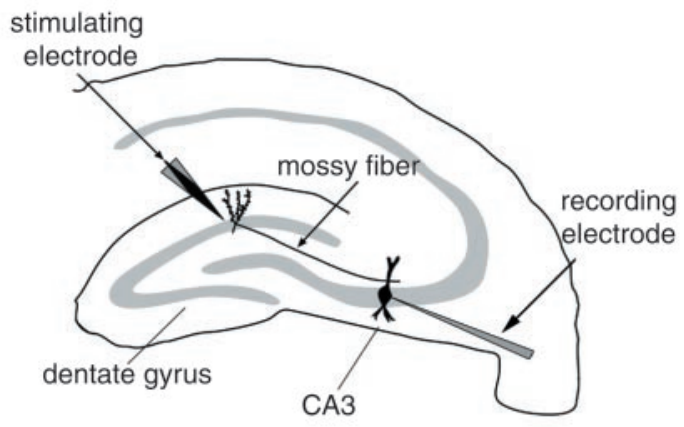

C

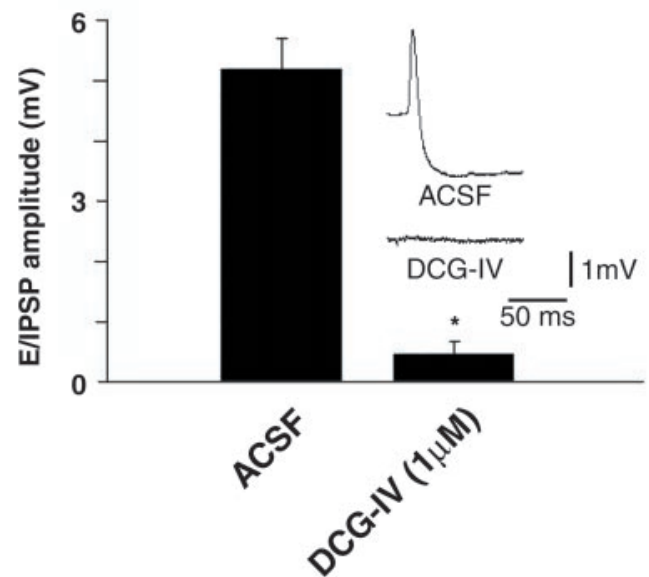

stimulus is larger than that to the first, is believed to reflect an increase in $p_{\mathrm{r}}$ to the second stimulus when residual $\mathrm{Ca}^{2+}$ from the first impulse sums with $\mathrm{Ca}^{2+}$ from the second (Wu and Saggau, 1994). In general, mossy fiber synapses exhibited a high $p_{\mathrm{Ca}}$; in 3 mm extracellular $\mathrm{Ca}^{2+}$, the average $p_{\mathrm{Ca}}$ was $0.84 \pm 0.05(n=31$ synapses). At six mossy fiber synapses in which $p_{\mathrm{Ca}}$ to single stimuli was $<1, p_{\mathrm{Ca}}$ increased from the first stimulus to the second stimulus $(0.31 \pm 0.1$ vs $0.98 \pm 0.02 ; p<0.002)$ when paired stimuli were administered with a $70-75 \mathrm{msec}$ interval (Fig. 2Cii). This demonstration of paired-pulse facilitation suggests that, in parallel with our observations at simple spines, $p_{\mathrm{Ca}}$ measured at complex spines reflects $p_{\mathrm{r}}$, the aggregate probability of transmitter release by all of the inputs to the imaged spine.

\section{Ultrastructural confirmation of identification of complex spines as thorny excrescences postsynaptic to mossy fiber terminals}

To confirm the identification of the optically characterized complex spines as thorny excrescences postsynaptic to mossy fibers, preparations were fixed after optical and electrophysiological recording and processed for electron microscopy. Comparison with confocal images allowed unambiguous identification of optically characterized spines in serial ultrathin sections (Fig. 3). These spines ( $n=3$ preparations) all displayed complex lobular morphology and received multiple synaptic contacts from presynaptic terminals containing clear round and dense-cored vesicles (Fig. 3D), characteristic of mossy fiber synapses in organotypic culture (Frotscher and Gähwiler, 1988). These observations, in conjunction with the electrophysiological and pharmacological observations described above, establish unambiguously that the complex spines monitored here by confocal microscopy are indeed thorny excrescences postsynaptic to mossy fiber terminals.

\section{Contribution of ionotropic glutamate receptors to the calcium transient}

Several mechanisms could underlie the rapid rise in $\mathrm{Ca}^{2+}$ at thorny excrescences. To establish the glutamatergic nature of the response, we examined the effect of the AMPA/kainate receptor antagonist CNQX $(20 \mu \mathrm{M})$. CNQX abolished both the EPSP $(7.1 \pm 1.2 \mathrm{mV}$ reduced to $-1.5 \pm 1.2 \mathrm{mV} ; p<0.005 ; n=5)$ and the EPSCaT $(0.6 \pm 0.2 \%$ of initial, "baseline," amplitude; $n=5$; $p<0.005$ ) (Fig. 4A,C). This indicates that a CNQX-sensitive, presumably AMPA receptor-mediated, local depolarization is essential for evoking EPSCaTs in complex spines. This depolarization could serve to open VACCs or to remove the voltagedependent $\mathrm{Mg}^{2+}$ block of NMDA receptors. To test whether the activation of NMDA receptors is responsible for the $\mathrm{Ca}^{2+}$ transient, we applied two different NMDA receptor antagonists. Both the irreversible NMDA receptor open-channel blocker MK-801 $(20 \mu \mathrm{M})$ and the competitive antagonist D-APV $(20 \mu \mathrm{M})$ significantly, but only partially, reduced the $\mathrm{Ca}^{2+}$ transient $(53 \pm 14 \%$, $n=4$ and $58 \pm 6 \%, n=4$ of baseline, respectively; $p<0.05$ for the combined data compared with control) (Fig. $4 B, C$ ). These values, implying that up to $47 \%$ of the $\mathrm{Ca}^{2+}$ transient is NMDAmediated, are overestimates, because simply resampling without drugs leads to a small reduction in EPSCaT amplitude ( $87 \pm 10 \%$ of baseline) (Fig. 4C, Control), presumably a consequence of indicator bleaching. Correction for this resampling reduction 

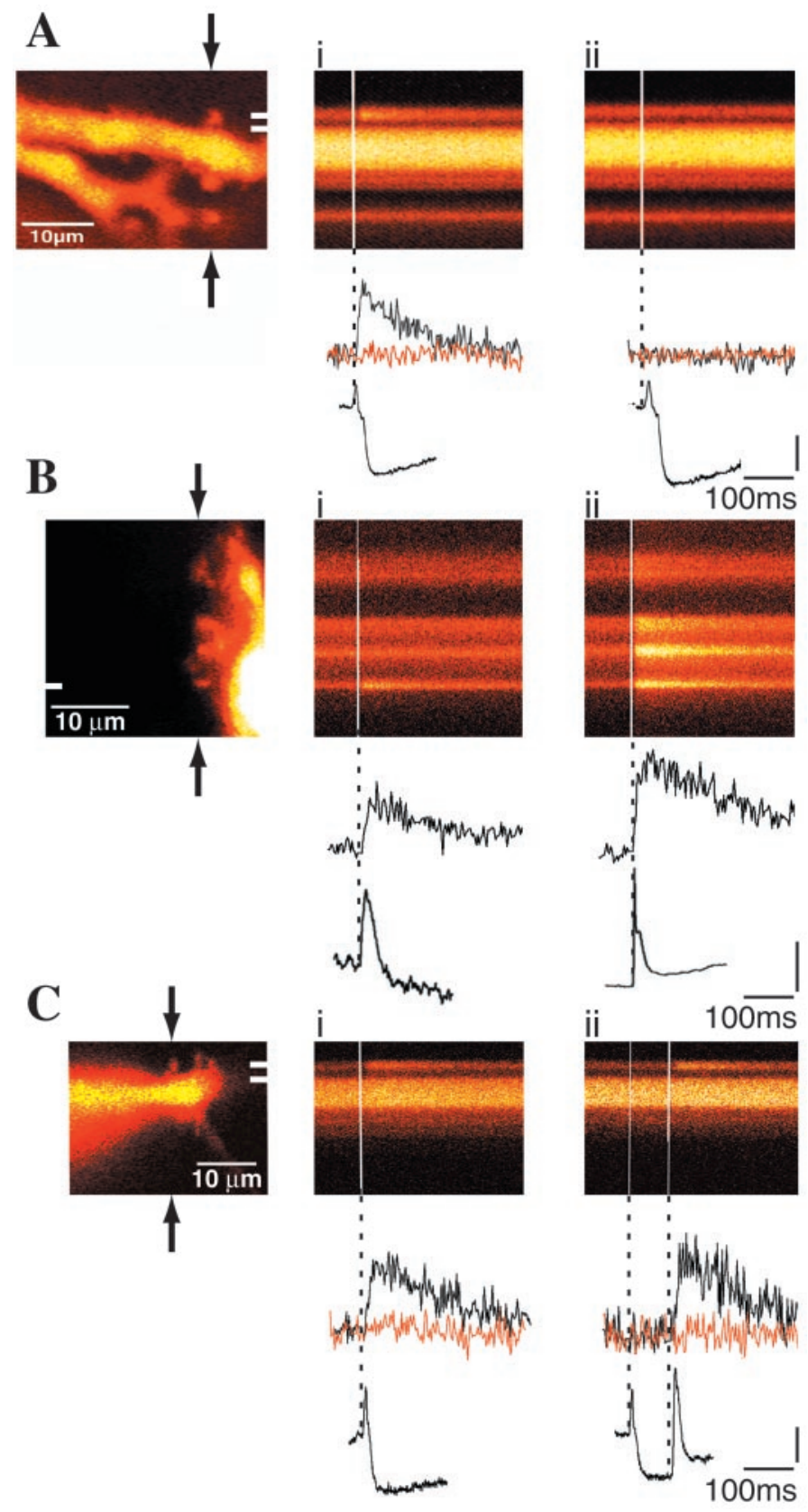

Figure 2. Confocal imaging of calcium transients in individual complex spines, elicited by subthreshold EPSPs. $A$, Left, Calcium indicator-filled proximal dendritic segment of a CA3 pyramidal neuron. Two line scans along the trajectory indicated by the arrows are shown in $A_{i}$ and $A_{i i}$. Below each line scan are the synchronously recorded somatic membrane potential (bottom black traces; note the compound synaptic response in $A_{i}$ and $A_{i i}$, with a small EPSP immediately followed by a large IPSP) and the $\mathrm{Ca}^{2+}$ transients (top traces; expressed as fractional change in fluorescence, $\Delta F / F$ ) in the spine (black) and in the immediately subjacent dendritic shaft (red) at the levels of the top and bottom fiducial marks, respectively, in the left panel. The vertical white lines (time stamps) in the line scans mark the delivery of a single stimulus via the stimulating electrode in the granule cell layer to activate mossy fibers projecting to the imaged cell. The line scan in $A_{i}$ shows an EPSCaT that is restricted to one thorny excrescence without spread to the dendritic shaft compartment. The line scan in $A_{i i}$ illustrates a failure of afferent stimulation to elicit an EPSCaT, presumably attributable to the failure of transmitter release at the investigated spine. B, Left, Calcium indicator-filled region of a CA3 pyramidal cell body and proximal apical dendrite. Line scans along the trajectory indicated by the arrows demonstrate an EPSCaT, evoked by a subthreshold EPSP, restricted to a single thorny excrescence $\left(B_{i}\right)$ at the suggests the NMDA-mediated component represents only $\sim 35 \%$ of the EPSCaT. In three cells in which APV was applied and stability maintained through drug washout, recovery of the $\mathrm{Ca}^{2+}$ transient was achieved after wash (to $87 \pm 12 \%$ of baseline, i.e., to control values for resampling) (Fig. $4 \mathrm{Bii}$ ).

What other sources could contribute to EPSCaTs at complex spines? One possibility is other ionotropic glutamate receptors; AMPA receptors lacking Q/R-edited GluR2 subunits are known to be $\mathrm{Ca}^{2+}$-permeable (Hollmann et al., 1991; Jia et al., 1996). A possible contribution of this source to the EPSCaT was investigated by using HPP-spermine $(10 \mu \mathrm{M})$, a specific antagonist of $\mathrm{Ca}^{2+}$-permeable AMPA receptors (Washburn and Dingledine, 1996). This drug had no effect on EPSCaT amplitudes (88.7 \pm $17 \%$ of baseline) (Fig. $4 C$ ), consistent with previous reports that $\mathrm{Ca}^{2+}$-permeable AMPA receptors are not present at mossy fiber-CA3 pyramidal synapses (Toth and McBain, 1998). Kainate receptors containing unedited versions of GluR5 and GluR6 subunits are also known to be $\mathrm{Ca}^{2+}$-permeable (Hollmann et al., 1991). However, kainate-mediated EPSCs at mossy fiber synapses have current-voltage relationships that are linear or show slight outward rectification (Castillo et al., 1997; Vignes and Collingridge, 1997), characteristic of $\mathrm{Ca}^{2+}$-impermeable kainate receptors and in contrast to the strong inward rectification exhibited by $\mathrm{Ca}^{2+}$-permeable kainate receptors (Burnashev et al., 1996). Furthermore, kainate receptor activation at the mossy fiber synapse requires high-frequency stimulation (Castillo et al., 1997; Vignes and Collingridge, 1997). Thus, it is unlikely that $\mathrm{Ca}^{2+}$ permeable kainate receptors contribute to the unitary EPSCaTs described here.

\section{Contribution of voltage-activated calcium channels to the calcium transient}

The local depolarization resulting from activation of AMPA receptors could generate the EPSCaT by opening VACCs. To test whether VACCs contribute to the transient, we tested the effects of several substances. The application of $\mathrm{Ni}^{2+}(100 \mu \mathrm{M})$, which blocks low-threshold T-type and high-threshold R-type VACCs (Wu et al., 1998), reduced the amplitude of the $\mathrm{Ca}^{2+}$ signal slightly but not significantly (74 $\pm 3 \%$ of baseline; $n=4$; $p=0.20$ ) (Fig. $5 B$ ), indicating that these channels are unlikely to contribute more than $\sim 15 \%$ of the EPSCaT (after correcting for resampling). Nifedipine, at a concentration $(20 \mu \mathrm{M})$ sufficient to reduce action potential-evoked $\mathrm{Ca}^{2+}$ transients at the soma by $49 \pm 14 \%(n=3)$, did not significantly reduce EPSCaT amplitudes ( $89 \pm 6 \%$ of baseline; $n=3 ; p=0.46$ ) (Fig. $5 A$ ), suggesting that L-type VACCs also do not contribute significantly to the synaptically evoked $\mathrm{Ca}^{2+}$ transients in complex spines.

Three additional VACCs remained to be considered: the high-

$\leftarrow$

level of the fiducial mark and a generalized $\mathrm{Ca}^{2+}$ transient in all structures in response to a suprathreshold EPSP $\left(B_{i i}\right)$. $C$, Additional examples of EPSCaTs, evoked by single $\left(C_{i}\right)$ or paired $\left(C_{i i} ; 75 \mathrm{msec}\right.$ interval $)$ stimuli, restricted to a single thorny excrescence (top black traces; as measured at the level of the top fiducial mark in the left panel) without affecting $\mathrm{Ca}^{2+}$ fluorescence in the immediately subjacent dendritic shaft (red traces and bottom fiducial mark); figure elements as in $A$. In the example in $C_{i i}$, transmission at this synapse failed in response to the first of the paired stimuli. In the false color "thermal" lookup table used in these confocal images, increasing fluorescence is denoted by colors from black through red to yellow and white. Vertical calibration bar: top traces, $A, 70 \% \Delta F / F ; B, 100 \%$; $C, 50 \%$; bottom traces, $A, 5 \mathrm{mV} ; B_{i}, 2 \mathrm{mV} ; B_{i i}, 30$ $\mathrm{mV} ; C, 3 \mathrm{mV}$. The resting membrane potential was $-77 \mathrm{mV}$ for the cell in $A,-77 \mathrm{mV}$ for the cell in $B$, and $-66 \mathrm{mV}$ for the cell in $C$. 
Figure 3. The identity of optically characterized complex spines as postsynaptic to mossy fibers is confirmed by electron microscopy. A, Line scan (right) along the trajectory indicated by arrows in the left confocal image shows an EPSCaT in one complex spine (blackwhite arrowhead and fiducial mark) in response to dentate gyrus stimulation. Two adjacent complex spines (black arrowheads) are not activated. $B$, Electron micrograph of an ultrathin section through the same cell; correspondence with the optical images (inset and $A$ ) is evident. $C$, Higher magnification view of the region in $B$ corresponding to the region outlined by white boxes in $A$ and inset in $B$. The three complex spines labeled by arrowheads in $A$ and $B$ are indicated by corresponding arrowheads. $D$, Higher magnification image of an adjacent serial section, showing the activated spine indicated by the blackwhite arrowhead in A-C. Black-white arrowheads indicate two synapses onto the complex spine, made by terminals containing both clear and dense-cored vesicles. Scale bar: $A, 9.5 \mu \mathrm{m} ; B, 6 \mu \mathrm{m}$; $C, 1.8 \mu \mathrm{m} ; D, 0.5 \mu \mathrm{m}$; inset in $B, 12 \mu \mathrm{m}$.
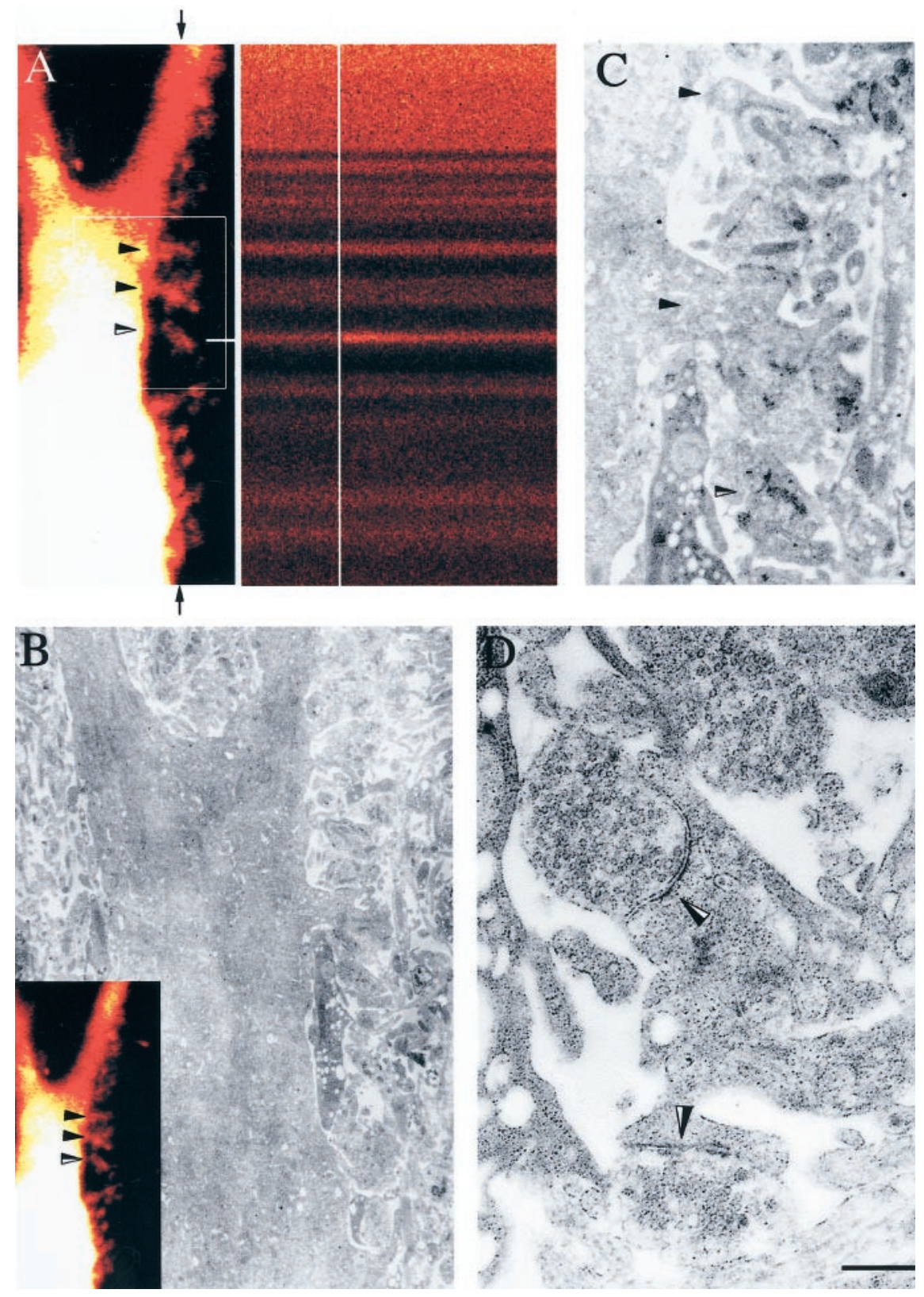

voltage activated N-, P-, and Q-types. Because these channels are known also to support transmitter release at mossy fiber terminals (Castillo et al., 1994), a direct evaluation of their effects on complex spine EPSCaTs is difficult. Therefore, to determine whether high-threshold VACCs are present on complex spines, backpropagating action potentials were elicited by injecting a current pulse (40-80 msec, $1 \mathrm{nA}$ ) into the CA3 pyramidal cell (Fig. 6B). The resultant $\mathrm{Ca}^{2+}$ transient is independent of transmitter release and therefore amenable to pharmacological manipulations that disrupt synaptic transmission. In all cases, the $\mathrm{Ca}^{2+}$ transient within the complex spine had the same onset latency and kinetics as the transient generated in the dendritic shaft (Fig. 6A). This suggests that action potential-evoked $\mathrm{Ca}^{2+}$ influx into the spine results from the activation of channels on the spine itself rather than from diffusion of $\mathrm{Ca}^{2+}$ from the dendritic shaft (Svoboda et al., 1996), in agreement with previous observations (Jaffe and Brown, 1997). The nonselective VACC blocker $\mathrm{Cd}^{2+}$
$(50 \mu \mathrm{M})$ completely eliminated action potential-evoked $\mathrm{Ca}^{2+}$ transients at complex spines $(0.2 \pm 1 \%$ of baseline; $n=6 ; p<$ 0.0005 ) (Fig. 6B,C); the effect was seen even at complex spines adjacent to the soma in which the block cannot be attributable to interference with action potential propagation. The widespectrum blocker of N-, P-, and Q-type VACCs, $\omega$-conotoxin MVIIC (2 $\mu \mathrm{M})$ (McDonough et al., 1996), also substantially reduced the action potential-evoked $\mathrm{Ca}^{2+}$ transients at complex spines ( $49.0 \pm 8 \%$ of baseline; $n=4 ; p<0.02)$, providing additional evidence that these channels are present and functional at complex spines.

As an additional test of the involvement of VACCs in mediating complex spine EPSCaTs, VACCs were inactivated by depolarizing the CA3 pyramidal cell. We reasoned that if VACCs are responsible for the NMDA receptor-independent component of the EPSCaT, then under experimental conditions in which VACCs are inactivated NMDA receptor antagonists should en- 
A.

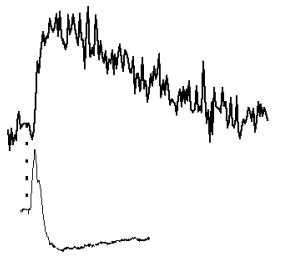

ACSF

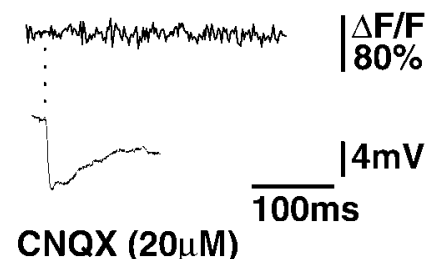

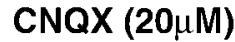

ii

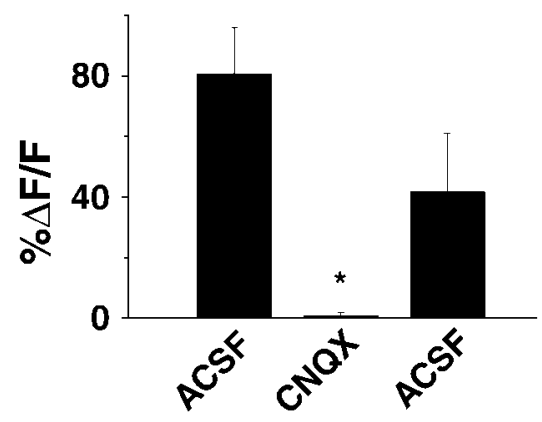

B.

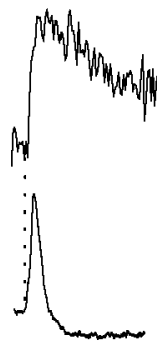

ACSF

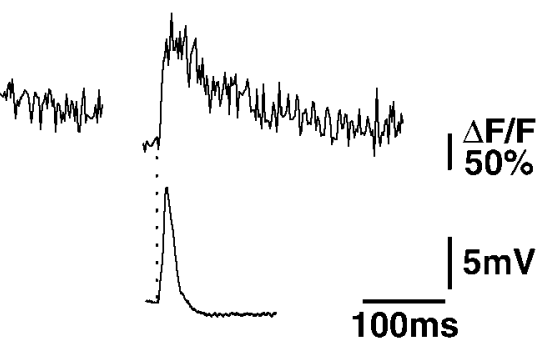

MK-801 (20 $\mu \mathrm{M})$ ii

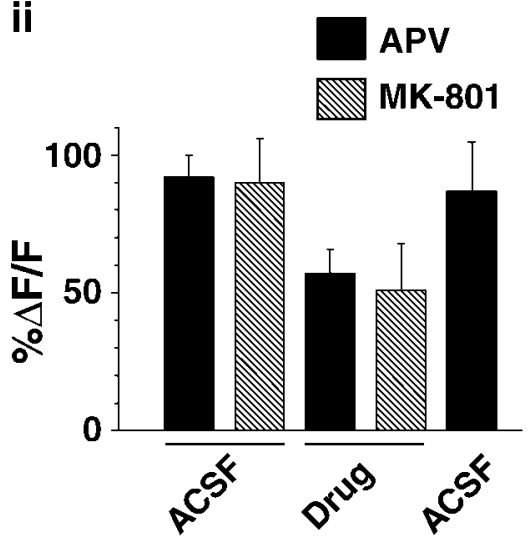

D

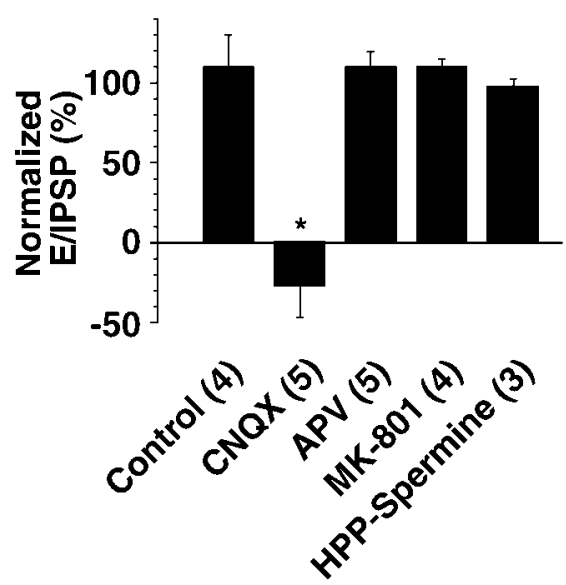

Figure 4. Ionotropic glutamate receptors mediate the $\mathrm{Ca}^{2+}$ signal seen at complex mossy fiber dendritic spines. $A_{i}$, The EPSCaT amplitude $(\% \Delta F / F)$ at an investigated thorny excrescence, and synchronously recorded somatic membrane potential (resting potential, -66 $\mathrm{mV}$ ), in response to a single stimulus. The AMPA/kainate receptor antagonist CNQX $(20 \mu \mathrm{M})$ abolishes both the EPSP and the $\mathrm{Ca}^{2+}$ signal; the IPSP component persists. $A_{i i}$, Summary histogram of the mean EPSCaT amplitude before, during, and after application of CNXQ $(n=5)$. Error bars represent SEM. $B_{i}$, The irreversible NMDA receptor antagonist MK $801(20 \mu \mathrm{M})$ partially reduces the $\mathrm{Ca}^{2+}$ signal at the mossy fiber spines but does not significantly change the EPSP (resting potential, $-73 \mathrm{mV}$ ). $B_{i i}$, Summary histogram of the mean EPSCaT amplitude before and after application of MK $801(n=4)$ and the reversible NMDA receptor antagonist APV $(25 \mu \mathrm{M} ; n=5)$, illustrating partial block of the signal by both drugs. $C$, Summary histogram of mean EPSCaT amplitudes (normalized to initial baseline EPSCaT amplitude) after different treatments. $D$, Mean peak synaptic response amplitude for the same series of experiments, normalized similarly. CNQX blocks the EPSP component of the compound synaptic waveform, whereas the other manipulations have no significant effect. Numbers in brackets indicate the number of experiments done for each group. ${ }^{*} p<0.05$, significantly different from control. tirely block the EPSCaT. Positive current (0.05-0.2 nA) was injected into the neuron (with $50 \mathrm{~mm}$ QX-314 in the microelectrode to suppress action potentials), depolarizing the membrane to -10 to $-15 \mathrm{mV}$ to inactivate VACCs. At these depolarized membrane potentials, APV completely blocked the EPSCaT $(-0.7 \pm 5 \%$ of baseline amplitude; $n=3 ; p<0.005$; compared with the smaller APV block at resting membrane potentials, $58 \pm$ $6 \%$ of baseline) (Fig. 6D). In conjunction with the lack of effect of $\mathrm{Ni}^{2+}$ and nifedipine, these experiments taken together support the conclusion that N-, P-, and/or Q-type high-threshold VACCs on thorny excrescences are activated by single synaptic events and are the major generators of EPSCaTs at these spines.

\section{Contribution of $\mathrm{Ca}^{2+}$ release from internal stores}

Our previous observations on simple spines in CA3 and CA1 pyramidal cells indicated that EPSCaTs result from amplification of NMDA receptor-mediated $\mathrm{Ca}^{2+}$ influx by the release of $\mathrm{Ca}^{2+}$ from internal stores within the spine (Emptage et al., 1999). To determine whether a similar amplification mechanism functions at the mossy fiber synapse, we added ryanodine $(20 \mu \mathrm{M})$ to the bathing medium. Ryanodine at this concentration binds to ryanodine receptors (RyRs), blocking CICR from internal stores (McPherson et al., 1991). In contrast to its nearly complete abolition of EPSCaTs at simple spines, ryanodine had no effect 
A

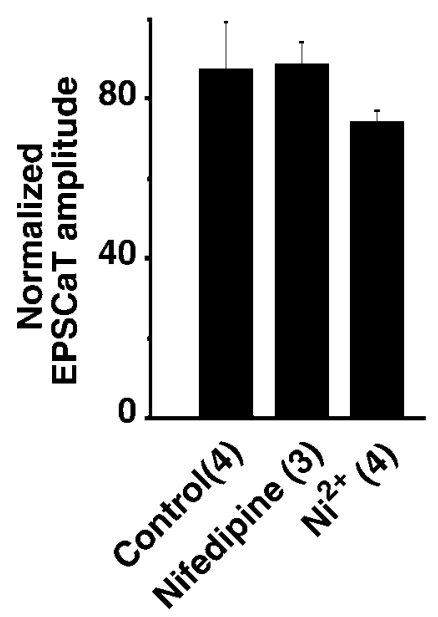

B

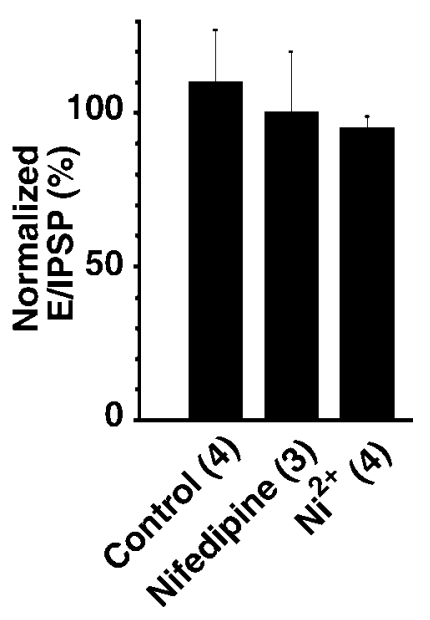

Figure 5. L-, T-, and R-type voltage-activated calcium channels are not major contributors to EPSCaTs at mossy fiber synapses. Summary histograms of mean EPSCaT amplitudes at complex spines $(\% \Delta F / F$, normalized as in Fig. 4) $(A)$ and synchronously recorded mean peak synaptic response amplitudes (normalized as percent of initial baseline synaptic response, as in Fig. 4) (B) after control change of ACSF or after application of the L-type VACC antagonist nifedipine $(20 \mu \mathrm{M})$ or the Tand R-type VACC antagonist $\mathrm{Ni}^{2+}(100 \mu \mathrm{M})$. Both substances are without significant effect on either the EPSP or the $\mathrm{Ca}^{2+}$ transient.

on EPSCaTs at complex spines $(\% \Delta F / F=100 \pm 29 \%$ of baseline; $n=4 ; p=0.40$ ) (Fig. $7 A$ ), indicating that RyR-mediated CICR does not contribute to these $\mathrm{Ca}^{2+}$ transients. However, internal stores may also release $\mathrm{Ca}^{2+}$ via activation of $\mathrm{IP}_{3}$ receptors by either $\mathrm{IP}_{3}$ or $\mathrm{Ca}^{2+}$ (Berridge, 1993). To test this possibility, cyclopiazonic acid (CPA) $(15-30 \mu \mathrm{M})$, a selective blocker of sarcoplasmic-endoplasmic reticulum $\mathrm{Ca}^{2+}$ /ATPase (SERCA pumps) (Seidler et al., 1989), was used to deplete the smooth endoplasmic reticulum-derived $\mathrm{Ca}^{2+}$ stores. In contrast to simple spines, in which CPA abolished EPSCaTs (Emptage et al., 1999), this drug did not decrease EPSCaT amplitudes at complex spines. Indeed, in striking contrast, CPA significantly increased EPSCaT amplitudes at complex spines [to $124 \pm 4 \%$ of baseline (equivalent to $\sim 140 \%$ after correction for resampling); $p<0.05 ; n=3$ ] (Fig. $7 A$ ), presumably reflecting a role of stores in buffering synaptically evoked $\mathrm{Ca}^{2+}$ transients in the spines.

\section{DISCUSSION}

Morphological studies including electron microscopy and $\mathrm{Zn}^{2+}$ histochemistry (Timm's staining) have demonstrated that mossy fiber terminals in organotypic hippocampal cultures maintain their normal complex structure and restricted distribution on CA3 pyramidal neurons (Robain et al., 1994; Pozzo Miller et al., 1996). The morphology, location, and ultrastructure of the complex spines studied here and the DCG-IV sensitivity of the EPSP suggest that the anatomy and physiology of mossy synapses in these organotypic cultures parallels that in the intact brain. Strong, tetanic synaptic stimulation has been shown previously to evoke $\mathrm{Ca}^{2+}$ transients in the proximal apical dendrite of these cells (Pozzo Miller et al., 1996; Jaffe and Brown, 1997). Here, we have demonstrated that subthreshold activation of mossy fiber synapses by single stimuli produces postsynaptic $\mathrm{Ca}^{2+}$ transients restricted to the spine. Thus, these complex spines, like the morphologically simple spines more commonly found on hippocampal pyramidal neurons, can be considered minimal com- partments of postsynaptic $\mathrm{Ca}^{2+}$ response (Yuste and Denk, 1995; Denk et al., 1996; Svoboda et al., 1996). The precise role of these localized $\mathrm{Ca}^{2+}$ transients is unresolved, but they are likely to mediate plastic as well as homeostatic processes in the spine. The increased resolution of our observations has permitted a characterization of the pharmacology of these $\mathrm{Ca}^{2+}$ transients, revealing that, in contrast to EPSCaTs at simple spines, single synaptically evoked $\mathrm{Ca}^{2+}$ transients at complex spines can be detected even in the absence of NMDA receptor activation and have no calcium store component. This ancillary role of NMDA receptors in generating postsynaptic $\mathrm{Ca}^{2+}$ transients at mossy fiber synapses is consistent with the low density of NMDA receptors found on complex spines (Monaghan et al., 1983; Jonas et al., 1993; Spruston et al., 1995) and, together with the other results presented here, implies that EPSCaTs at these synapses result mainly from AMPA-gated opening of VACCs.

VACCs are known to be present on dendritic spines (Mills et al., 1994; Segal, 1995) and to be activated by backpropagating action potentials (Jaffe et al., 1994; Yuste and Denk, 1995), but whether they can be activated by subthreshold synaptic input has been controversial. The presence of VACCs endows the spine with excitable membrane, and it has been suggested that excitatory synaptic input may initiate action potentials in such excitable spines (Segev and Rall, 1998). The present results indicate that VACCs on complex spines are indeed activated not only by backpropagating action potentials but also by subthreshold synaptic activation. However, the former generate larger amplitude calcium transients in the spines than do the latter, implying that synaptic activation of spine VACCs is graded rather than all-ornone as has been suggested previously on theoretical grounds (Segev and Rall, 1998).

We have not been able to specify the VACCs responsible for the mossy fiber EPSCaT. The failure of nifedipine to affect these responses while reducing somatic $\mathrm{Ca}^{2+}$ transients caused by action potentials is consistent with immunohistochemical evidence that L-type VACCs occur predominantly on the soma, rather than dendrites, of CA3 neurons (Elliott et al., 1995). A substantial role for low-threshold T-type and high-threshold R-type VACCs was eliminated by the lack of significant effect of $\mathrm{Ni}^{2+}$ on the EPSCaT. A definitive test of the selective involvement of the remaining VACCs, P-, Q-, and N-type, in generating the complex spine EPSCaT was precluded by the involvement of these channels in transmitter release from the mossy fiber terminal (Castillo et al., 1994). It was possible, however, to confirm the presence of functional high-threshold VACCs on complex spines, because $\mathrm{Cd}^{2+}$ abolished, and $\omega$-conotoxin MVIIC reduced, action potential-elicited $\mathrm{Ca}^{2+}$ transients whose onset was too rapid to be attributable to diffusion of $\mathrm{Ca}^{2+}$ into the spines from the dendritic shaft (Svoboda et al., 1997). Furthermore, depolarization of the neuron to levels that should inactivate VACCs rendered EPSCaTs fully blockable by the NMDA-receptor antagonist APV.

CPA increases the EPSCaT amplitude at complex spines, indicating that these spines contain internal calcium stores that function (at least at low-stimulation frequencies) mainly in buffering, rather than generating, these EPSCaTs. The considerable difference between sources of the synaptic $\mathrm{Ca}^{2+}$ transient at thorny excrescences (in which the $\mathrm{Ca}^{2+}$ comes mainly from VACCs, less from NMDA receptors, and not at all from CICR) and at simple spines [in which the transient arises from NMDA receptor-mediated CICR, with minimal contribution from VACCs (Emptage et al., 1999)] in the same CA3 pyramidal cells 

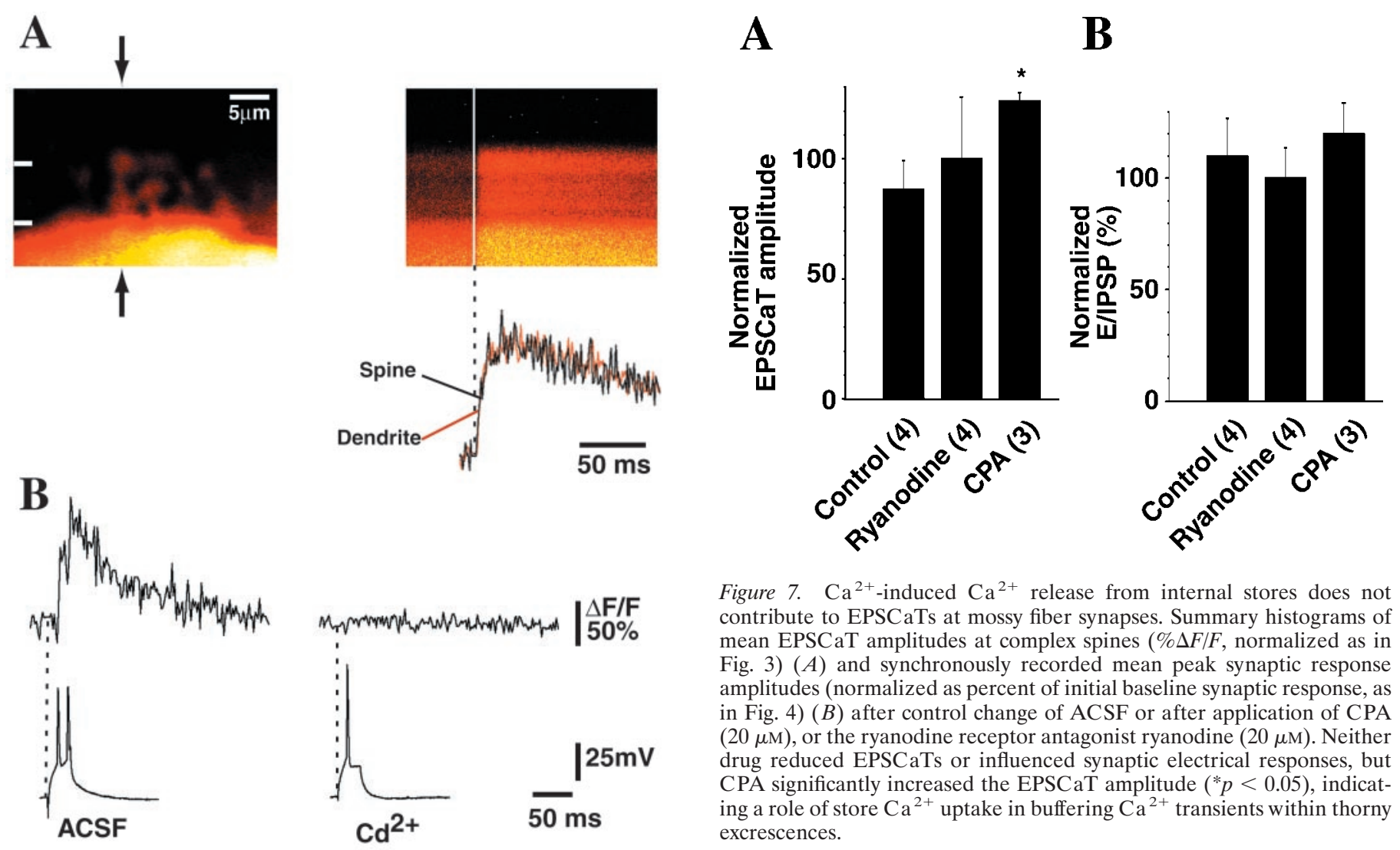
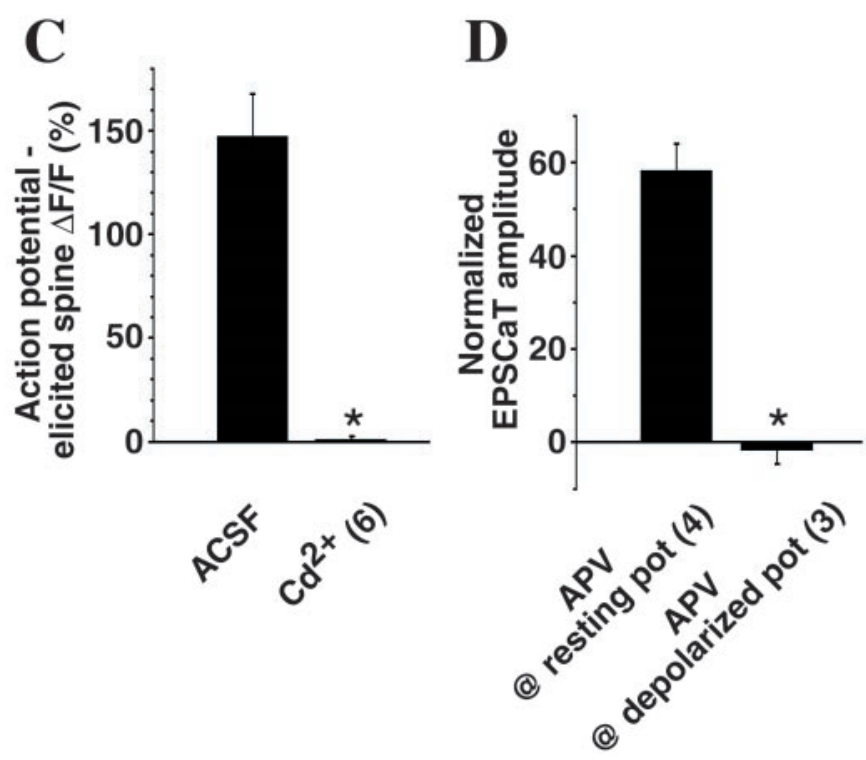

Figure 6. High-threshold voltage-activated calcium channels are present at thorny excrescences and are major contributors to the EPSCaT. $A$, $\mathrm{Ca}^{2+}$ indicator-filled complex spines on the proximal apical dendritic shaft of a CA3 pyramidal neuron (left). A line scan (right) along the trajectory indicated by the arrows in the left shows the $\mathrm{Ca}^{2+}$ transients elicited by an action potential triggered by a suprathreshold EPSP (stimulus to dentate gyrus at time marked by the vertical white line). The quantified transients in the spine (black) and subjacent dendritic shaft (red), at the levels in the left indicated by the top and bottom fiducial marks, respectively, are shown below the line scan, scaled to the same peak amplitude. The two traces are temporally indistinguishable, indicating that the $\mathrm{Ca}^{2+}$ transient arises independently in the spine and not by diffusion of $\mathrm{Ca}^{2+}$ from the dendritic shaft. $B$, The $\mathrm{Ca}^{2+}$ transient in an individual complex spine evoked by intrasomatic current injection (left top
Figure 7. $\mathrm{Ca}^{2+}$-induced $\mathrm{Ca}^{2+}$ release from internal stores does not contribute to EPSCaTs at mossy fiber synapses. Summary histograms of mean EPSCaT amplitudes at complex spines $(\% \Delta F / F$, normalized as in Fig. 3) $(A)$ and synchronously recorded mean peak synaptic response amplitudes (normalized as percent of initial baseline synaptic response, as in Fig. 4) ( $B)$ after control change of ACSF or after application of CPA $(20 \mu \mathrm{M})$, or the ryanodine receptor antagonist ryanodine $(20 \mu \mathrm{M})$. Neither drug reduced EPSCaTs or influenced synaptic electrical responses, but CPA significantly increased the EPSCaT amplitude $\left({ }^{*} p<0.05\right)$, indicating a role of store $\mathrm{Ca}^{2+}$ uptake in buffering $\mathrm{Ca}^{2+}$ transients within thorny excrescences.

presumably reflects a genuine difference between these types of synapse rather than a peculiarity of organotypic cultures (Kovalchuk et al., 2000). Why spines on the same cell should differ in this way is unclear. Activation of the mossy synapse, however, elicits a much larger EPSP than does activation of commissural or collateral synapses; this has led to the suggestion that mossy fiber input may serve as a "teacher" controlling plasticity at more distal, simple spine synapses (Marr, 1971; Carnevale et al., 1997; Henze et al., 2000). The more proximal location of the mossy synapse may contribute to its stronger effect on the postsynaptic cell (particularly in triggering action potentials), but so may amplification of the response by the excitable complex spine. The greater synaptic activation of VACCs in thorny excrescences than in simple spines may in turn reflect the different geometry of these spines (Segev and Rall, 1988; Rusakov et al., 1996) or differences in density or subtype of channels. Changes in the properties or deployment of postsynaptic VACCs,

\section{$\leftarrow$}

trace; $\% \Delta F / F)$ is entirely blocked by the broad-spectrum VACC antagonist $\mathrm{Cd}^{2+}(50 \mu \mathrm{M}$; right top trace); the synchronously recorded action potentials (bottom traces) are unaffected. The dotted line indicates the onset of the depolarizing current injection. Note that the second action potential at left is reflected in a second peak in the fluorescence trace, establishing that single action potentials do not saturate the indicator in these spines. The resting membrane potential was $-73 \mathrm{mV}$ for this cell. $C$, Summary histogram of amplitudes of action potential-evoked $\mathrm{Ca}^{2+}$ transients in complex spines $(\% \Delta F / F)$ showing reduction in the presence of $\mathrm{Cd}^{2+}(n=6 ; p<0.0005)$. $D$, EPSCaTs are wholly NMDA receptordependent at depolarized membrane potentials. Summary histograms comparing effects of APV on mean EPSCaT amplitudes $(\% \Delta F / F$, normalized as in Fig. 4) with the cell at resting membrane potential and the greater reduction by APV during injection of depolarizing current to inactivate $\operatorname{VACCs}\left({ }^{*} p<0.005\right)$. 
no less than of glutamate receptors, could contribute to longlasting synaptic plasticity (Shepherd et al., 1985).

\section{REFERENCES}

Berridge MJ (1993) Inositol trisphosphate and calcium signalling. Nature 361:315-325.

Bliss TV, Collingridge GL (1993) A synaptic model of memory: longterm potentiation in the hippocampus. Nature 361:31-39.

Burnashev N, Villarroel A, Sakmann B (1996) Dimensions and ion selectivity of recombinant AMPA and kainate receptor channels and their dependence on $\mathrm{Q} / \mathrm{R}$ site residues. J Physiol (Lond) 496:165-173.

Carnevale NT, Tsai KY, Claiborne BJ, Brown TH (1997) Comparative electrotonic analysis of three classes of rat hippocampal neurons. J Neurophysiol 78:703-720.

Castillo PE, Weisskopf MG, Nicoll RA (1994) The role of $\mathrm{Ca}^{2+}$ channels in hippocampal mossy fiber synaptic transmission and long-term potentiation. Neuron 12:261-269.

Castillo PE, Malenka RC, Nicoll RA (1997) Kainate receptors mediate a slow postsynaptic current in hippocampal CA3 neurons. Nature 388:182-186.

Chicurel ME, Harris KM (1992) Three-dimensional analysis of the structure and composition of CA3 branched dendritic spines and their synaptic relationships with mossy fiber boutons in the rat hippocampus. J Comp Neurol 325:169-182.

Denk W, Yuste R, Svoboda K, Tank DW (1996) Imaging calcium dynamics in dendritic spines. Curr Opin Neurobiol 6:372-378.

Elliott EM, Malouf AT, Catterall WA (1995) Role of calcium channel subtypes in calcium transients in hippocampal CA3 neurons. J Neurosci 15:6433-6444.

Emptage N, Bliss TV, Fine A (1999) Single synaptic events evoke NMDA receptor-mediated release of calcium from internal stores in hippocampal dendritic spines. Neuron 22:115-124.

Frotscher M, Gähwiler BH (1988) Synaptic organization of intracellularly stained CA3 pyramidal neurons in slice cultures of rat hippocampus. Neuroscience 24:541-551.

Henze DA, Urban NN, Barrionuevo G (2000) The multifarious hippocampal mossy fiber pathway: a review. Neuroscience 98:407-427.

Hollmann M, Hartley M, Heinemann S (1991) $\mathrm{Ca}^{2+}$ permeability of KA-AMPA-gated glutamate receptor channels depends on subunit composition. Science 252:851-853.

Jaffe DB, Brown TH (1997) Calcium dynamics in thorny excrescences of CA3 pyramidal neurons. J Neurophysiol 78:10-18.

Jaffe DB, Fisher SA, Brown TH (1994) Confocal laser scanning microscopy reveals voltage-gated calcium signals within hippocampal dendritic spines. J Neurobiol 25:220-233.

Jia ZP, Agopyan N, Miu P, Xiong ZG, Henderson J, Gerlai R, Taverna FA, Velumian A, MacDonald J, Carlen P, Abramow-Newerly W, Roder J (1996) Enhanced LTP in mice deficient in the AMPA receptor GluR2. Neuron 17:945-956.

Jonas P, Major G, Sakmann B (1993) Quantal components of unitary EPSCs at the mossy fibre synapse on CA3 pyramidal cells of rat hippocampus. J Physiol (Lond) 472:615-663.

Kamiya H, Shinozaki H, Yamamoto C (1996) Activation of metabotropic glutamate receptor type 2/3 suppresses transmission at rat hippocampal mossy fibre synapses. J Physiol (Lond) 493:447-455.

Koester HJ, Sakmann B (1998) Calcium dynamics in single spines during coincident pre- and postsynaptic activity depend on relative timing of back-propagating action potentials and subthreshold excitatory postsynaptic potentials. Proc Natl Acad Sci USA 95:9596-9601.

Kovalchuk Y, Eilers J, Lisman J, Konnerth A (2000) NMDA receptormediated subthreshold $\mathrm{Ca}(2+)$ signals in spines of hippocampal neurons. J Neurosci 20:1791-1799.

Magee JC, Christofi G, Miyakawa H, Christie B, Lasser-Ross N, Johnston D (1995) Subthreshold synaptic activation of voltage-gated $\mathrm{Ca}^{2+}$ channels mediates a localized $\mathrm{Ca}^{2+}$ influx into the dendrites of hippocampal pyramidal neurons. J Neurophysiol 74:1335-1342.

Mainen ZF, Malinow R, Svoboda K (1999) Synaptic calcium transients in single spines indicate that NMDA receptors are not saturated. Nature 399:151-155.

Malinow R, Otmakhov N, Blum KI, Lisman J (1994) Visualizing hippocampal synaptic function by optical detection of $\mathrm{Ca}^{2+}$ entry through the $N$-methyl-D-aspartate channel. Proc Natl Acad Sci USA 91:8170-8174.

Marr D (1971) Simple memory: a theory for archicortex. Phil Trans Roy Soc Lond B Biol Sci 262:23-81.

McDonough SI, Swartz KJ, Mintz IM, Boland LM, Bean BP (1996)
Inhibition of calcium channels in rat central and peripheral neurons by omega-conotoxin MVIIC. J Neurosci 16:2612-2623.

McPherson PS, Kim YK, Valdivia H, Knudson CM, Takekura H, Franzini-Armstrong C, Coronado R, Campbell KP (1991) The brain ryanodine receptor: a caffeine-sensitive calcium release channel. Neuron $7: 17-25$.

Mills LR, Niesen CE, So AP, Carlen PL, Spigelman I, Jones OT (1994) $\mathrm{N}$-type $\mathrm{Ca}^{2+}$ channels are located on somata, dendrites, and a subpopulation of dendritic spines on live hippocampal pyramidal neurons. J Neurosci 14:6815-6824.

Monaghan DT, Holets VR, Toy DW, Cotman CW (1983) Anatomical distributions of four pharmacologically distinct $3 \mathrm{H}$-L-glutamate binding sites. Nature 306:176-179.

Müller W, Connor JA (1991) Dendritic spines as individual neuronal compartments for synaptic $\mathrm{Ca}^{2+}$ responses. Nature 354:73-76.

Pozzo Miller LD, Petrozzino JJ, Golarai G, Connor JA (1996) $\mathrm{Ca}^{2+}$ release from intracellular stores induced by afferent stimulation of CA3 pyramidal neurons in hippocampal slices. J Neurophysiol 76:554-562.

Ramon Y Cajal S (1911) Histologie du Systeme Nerveux de l'Homme et des Vertebres. Paris: Maloine.

Robain O, Barbin G, Billette de Villemeur T, Jardin L, Jahchan T, Ben-Ari Y (1994) Development of mossy fiber synapses in hippocampal slice culture. Brain Res Dev Brain Res 80:244-250.

Rusakov DA, Stewart MG, Korogod SM (1996) Branching of active dendritic spines as a mechanism for controlling synaptic efficacy. Neuroscience 75:315-323.

Schiller J, Schiller Y, Clapham DE (1998) NMDA receptors amplify calcium influx into dendritic spines during associative pre- and postsynaptic activation. Nat Neurosci 1:114-118.

Segal M (1995) Dendritic spines for neuroprotection: a hypothesis. Trends Neurosci 18:468-471.

Segev I, Rall W (1988) Computational study of an excitable dendritic spine. J Neurophysiol 60:499-523.

Segev I, Rall W (1998) Excitable dendrites and spines: earlier theoretical insights elucidate recent direct observations. Trends Neurosci 21:453-460.

Seidler NW, Jona I, Vegh M, Martonosi A (1989) Cyclopiazonic acid is a specific inhibitor of the $\mathrm{Ca}^{2+}$-ATPase of sarcoplasmic reticulum. J Biol Chem 264:17816-17823.

Shepherd GM (1996) The dendritic spine: a multifunctional integrative unit. J Neurophysiol 75:2197-2210.

Shepherd GM, Brayton RK, Miller JP, Segev I, Rinzel J, Rall W (1985) Signal enhancement in distal cortical dendrites by means of interactions between active dendritic spines. Proc Natl Acad Sci USA 82:2192-2195.

Shigemoto R, Kinoshita A, Wada E, Nomura S, Ohishi H, Takada M, Flor PJ, Neki A, Abe T, Nakanishi S, Mizuno N (1997) Differential presynaptic localization of metabotropic glutamate receptor subtypes in the rat hippocampus. J Neurosci 17:7503-7522.

Spruston N, Jonas P, Sakmann B (1995) Dendritic glutamate receptor channels in rat hippocampal CA3 and CA1 pyramidal neurons. J Physiol (Lond) 482:325-352.

Stoppini L, Buchs PA, Muller D (1991) A simple method for organotypic cultures of nervous tissue. J Neurosci Methods 37:173-182.

Svoboda K, Tank DW, Denk W (1996) Direct measurement of coupling between dendritic spines and shafts. Science 272:716-719.

Svoboda K, Denk W, Kleinfeld D, Tank DW (1997) In vivo dendritic calcium dynamics in neocortical pyramidal neurons. Nature 385:161-165

Toth K, McBain CJ (1998) Afferent-specific innervation of two distinct AMPA receptor subtypes on single hippocampal interneurons. Nat Neurosci 1:572-578.

Vignes M, Collingridge GL (1997) The synaptic activation of kainate receptors. Nature 388:179-182.

Washburn MS, Dingledine R (1996) Block of alpha-amino-3-hydroxy-5methyl-4-isoxazolepropionic acid (AMPA) receptors by polyamines and polyamine toxins. J Pharmacol Exp Ther 278:669-678.

Wu LG, Saggau P (1994) Presynaptic calcium is increased during normal synaptic transmission and paired-pulse facilitation, but not in long-term potentiation in area CA1 of hippocampus. J Neurosci 14:645-654.

Wu LG, Borst JG, Sakmann B (1998) R-type Ca ${ }^{2+}$ currents evoke transmitter release at a rat central synapse. Proc Natl Acad Sci USA 95:4720-4725

Yuste R, Denk W (1995) Dendritic spines as basic functional units of neuronal integration. Nature 375:682-684.

Yuste R, Majewska A, Cash SS, Denk W (1999) Mechanisms of calcium influx into hippocampal spines: heterogeneity among spines, coincidence detection by NMDA receptors, and optical quantal analysis. J Neurosci 19:1976-1987. 